ORL 1973;35:129-131

\title{
Dedication to Prof. Gerlings
}

This number of ORL is dedicated to a man who has been a devoted ear, nose and throat doctor for 40 years - to Pieter Godefridus Gerlings, born in Amsterdam in 1905. Gerlings always was a serious man who worked very hard for his patients, for his students, for the scientific societies. His almost encyclopedical knowledge of the scientific literature in our field was astonishing to those who met him for the first time, and a

130 Dedication to Prof. Gerlings

great source of help for those who knew him better. Names, titles, journals, and years were remembered with photographic precision. The only slight errors I have been able to detect were the page numbers.

His great care and precision as a surgeon helped not only his patients, but certainly also his students and co-workers. Gerlings has been a teacher from the beginning of his career, and many ear, nose, and throat specialists in Holland have been learning from him the small but so important details of all kinds of operations. The importance of systematic and careful inspection after the end of an operation became very clear when, with a kind smile on his face, Gerlings, who had assisted his younger co-worker, took a curet and brought forward an unexpected amount of granulation tissue from a little niche in a mastoid - or maxillary - cavity, or indicated a little bleeding vessel.

Gerlings has written a hundred scientific papers, nearly all of them descriptions of clinical cases and problems looked at from the point of view of the anatomist, the anatomopathologist or the histologist.

His first work of interest was a description of the clinical importance of tonsillectomy. It was his academical thesis and gave a lot of new information. It is also proof of the speed of time and chance of knowledge and interest. Only 40 years ago, tonsillectomy was quite a topic.

Gerlings also did a lot of work for the development of what was then the young child of ENT endoscopy. The surgery of petrositis, almost vanished from the earth nowadays, was a problem that Gerlings attacked with great skill and success.

It is no wonder that Gerlings, as a worker on problems in the entire field of otorhinolaryngology, has also edited textbooks for students and doctors. In 1949, his book on ENT diseases in children appeared in Dutch. In the preface, de Kleyn remarked that he preferred textbooks written by one man to those written by many authors, but only if the one writer really knew his field in all details as in this book.

He also edited for many years the Dutch textbook on ENT, written originally by his chief, Burger, and later by a large group of leading Dutch and Belgian otolaryngologists. The last completely rewritten edition appeared recently.

Gerlings has been a member of the Collegium ORLAS since 1947.

He was an editor of the reports of the 5th International Congress in Amsterdam, 1953, and secretary of the 'Nederlandse Keel-, Neus-Oor-heelkundige Vereeniging' from 1936 until 1945. In 1970, he was made an honorary member of this society.

Dedication to Prof. Gerlings 
131

The greater part of his life was spent as a University teacher; but he also had a very large number of private patients. In 1958, he was nominated as professor and head of the Department of ENT at the State University of Utrecht.

He is retiring now after 40 years of work. His many friends wish him the 'otium cum dignitate' which he has certainly earned; they will surely not forget the kindness, integrity, learning, and skill of the doctor, the teacher, and the friend after his retiring. The memory will live in their hearts. A token of it is this volume.

Amsterdam, September 1972

L. B. W. JONGKEES 